\title{
Autoimagen marginal: uma manifestação semiótica da representatividade feminina
}

LUCIANA BerLeze

Universidade Tuiuti do Paraná/UTP - mestranda 


\section{Resumo}

A proposta deste artigo é analisar as manifestações semióticas que se operam na construção de efeito de sentido nas fotografias do livro Autoimagen Marginal, de Evelyn Ruman, a fim de perceber como essas fotografias podem ser um instrumento de mediação simbólica da representação da identidade feminina, num ambiente de enclausuramento e de insanidade.

\section{Palavras-chave}

autoimagem, fotografia, construção, espelho, feminino, clausura, insanidade

\section{Abstract}

This article proposal is to analyze the semiotic manifestations that operate on the construction of sense effect in the photographs of the book Autoimagem Marginal, from Evelyn Ruman, in order to perceive how these photographs can be an instrument of symbolic mediation of feminine identity representation in an environment of enclosure and of insanity.

\section{Key words}

self-image, photography, construction, mirrors, feminine, enclosure, insanity 
proposta deste artigo é analisar as manifestações semióticas que se operam na construção de efeito de sentido nas fotografias do livro Autoimagen Marginal, de Evelyn Ruman (1998) Em princípio a análise será direcionada tomando como base a questão da segunda realidade da fotografia, a do assunto representado, de que trata Boris Kossoy (2000). A fotografia, diferente daquilo que está sendo registrado, tem uma realidade própria, construída, e faz uma transposição de dimensões, da realidade visual do assunto selecionado no contexto da vida para o da representação.

Desse modo, a realidade da fotografia não corresponde necessariamente à verdade histórica, mas é construída para dar um efeito de sentido de realidade. É dentro deste parâmetro que analisamos as imagens não como realidade do mundo natural, mas como construção de uma realidade inerente à enunciação proposta.

Verificando as fotografias do livro de Evelyn Ruman, percebemos que o trabalho realizado vai além do ato de fotografar. Das 36 fotografias editadas, treze apresentam-se sem interferência alguma, enquanto dois terços delas sofreram intervenções através da pintura posterior do papel fotográfico. Estas intervenções parecem feitas com diferentes materiais, como tinta guache e caneta hidrocor, e foram elaboradas pelas próprias fotografadas.

Para a análise do material proposto, deve-se levar em conta que as fotografadas, todas mulheres e reclusas de um instituto psiquiátrico ou de um centro de recuperação social, escolheram, dentre várias imagens, aquelas em que melhor se percebiam representadas para a posterior interferência. Este dado amplia a visão analítica deste artigo porque oferece um primeiro pressuposto inerente à linguagem fotográfica que é a sua questão especular, o simulacro do que vemos e, neste caso, de como nos vemos espelhados pelo olhar 
do outro. E a posterior interferência estabelece parâmetros de como as fotografadas gostariam de se ver reproduzidas. Trata-se, portanto, da fotografia enquanto representatividade nas suas duas faces, $o$ simulacro de como estas mulheres acreditam que sejam e de como desejariam parecer para o outro.

A enunciação desse texto visual estabelece, então, uma mediação simbólica da representação feminina com relação à cultura e aos estereótipos femininos agregados por esta mesma cultura.

E é dentro deste parâmetro que a análise do texto se pauta, a fim de buscar quais ferramentas semióticas foram utilizadas para a construção de efeito de sentido que manifeste esta mediação pretendida.

Utilizando como fundamentação teórica o projeto semiótico greimasiano, procuramos trilhar o percurso gerativo de sentido do texto visual como um todo, examinando apenas algumas fotografias isoladas com a intenção de exemplificar melhor as idéias abordadas neste trabalho.

\section{Percurso gerativo de sentido}

Autoimagen marginal é um texto visual figurativo cujo nível temático aborda a questão da feminilidade vivida parcialmente por uma situação de detenção, sustentada por fatores psicológicos ou de readequação social. Deste modo, a identidade feminina vista como liberdade é trabalhada no tex to como sendo eufórica e a privação desta identidade vista como opressão é disfórica.

Esta oposição euforia $v s$. disforia é trabalhada em diferentes aspectos. A opressão manifesta-se num primeiro momento pela condição de dominação da fotógrafa em relação à fotografada. $O$ fotógrafo, o operator para Barthes (1984), detém o poder de escolha do momento a ser registrado, do ângulo, da técnica, incluindo a câmera, lentes, filme, entre outros, que determinam a maneira em que o sujeito olhado será percebido. É a caracterização do fotógrafo-caçador em relação ao fotografado-caça.

Mas, diferente do provável, neste jogo de relações pessoais que compreende este tipo de fotografia, a seleção do que será mostrado não é do sujeito que olha. A liberdade manifesta-se, então, 
pela possibilidade de escolha da fotografada em relação à imagem na qual se percebe melhor representada e pela possibilidade de interferência posterior a que a fotografia está sujeita através da pintura, inclusive pelo uso da cor e material empregados.

Outra aspectualização da opressão como traço disfórico é a delimitação do espaço na fotografia como referência à condição de enclausuramento a que está submetida a fotografada. O espaço que surge é sempre um simulacro de imposição de limites, um muro, grade ou parede que serve de fundo para a composição da imagem, ainda que a fotografia se sirva da luz natural e tenha sido produzida num local externo.

O espaço figurativiza-se, então, como elemento de opressão, espaço fechado, demarcado, remetendo à lembrança de que o sujeito fotografado vive num ambiente de confinamento. Em algumas interferências esse elemento apresenta-se como recorrência, visto que para a pintura do espaço se aplicoli cor escura, sombria ou exageradamente forte, como na fotografia 1.

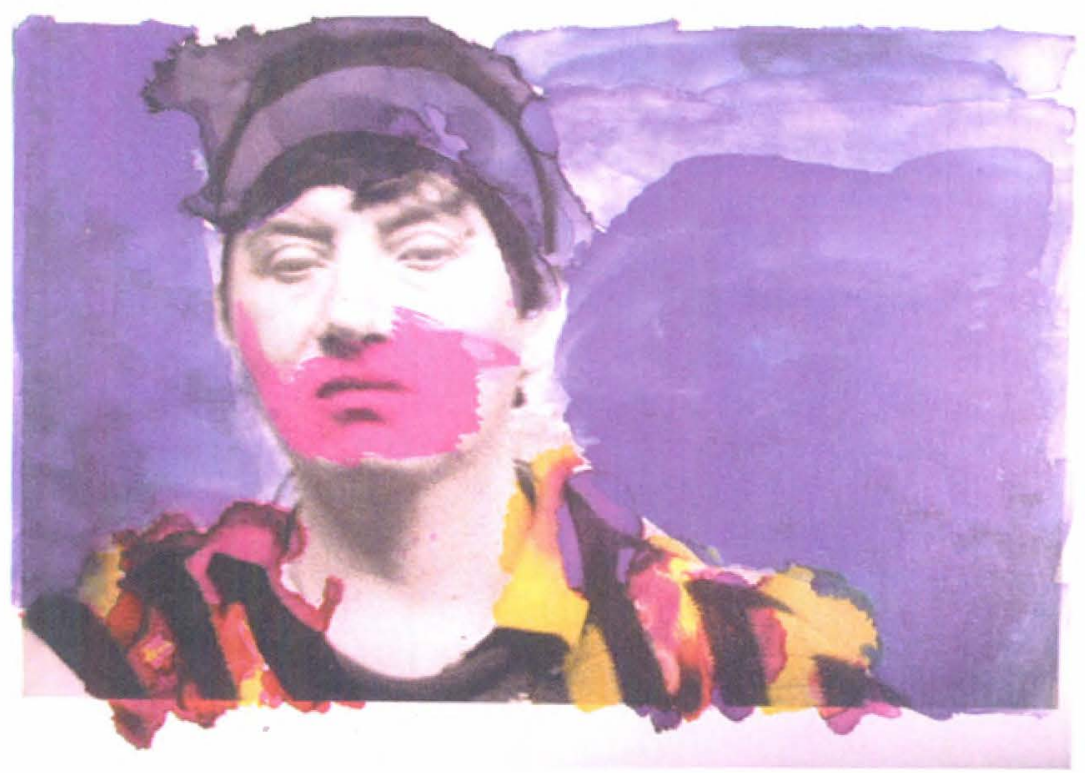


En outros desenhos, o espaço, como elemento disfórico. metamorfoseou-se em elemento eufórico. ou como um desejo de que assim o fosse, com o uso de cores claras e suaves, como azul, rosa ou amarelo, principalmente compartilhadas for garotas adolescentes, do centro de reabilitação. Neste caso, percebe-se um anseio pela liberdide ou uma revalorização pela liberdade perdida.

A exceção destá série é a fotografia 2 na qual aparece, em condição única, uma janela. Este tipo de elementc espacial, além de eufórico en relação às demais, pois abre uma pcssibilidade aberta de campo ce visão, foi pintado de cor rosa, vibrante, o oposto dos elementos internos, todos em tom pastel, apagado, triste, incluindo a própria fotografada. A cor rosa na janela oferece uma ilusão de que o mundo fora do limite do local em que a pers snagem se encontra é mais colorido ou mais intenso do que a realidade vivida ali.

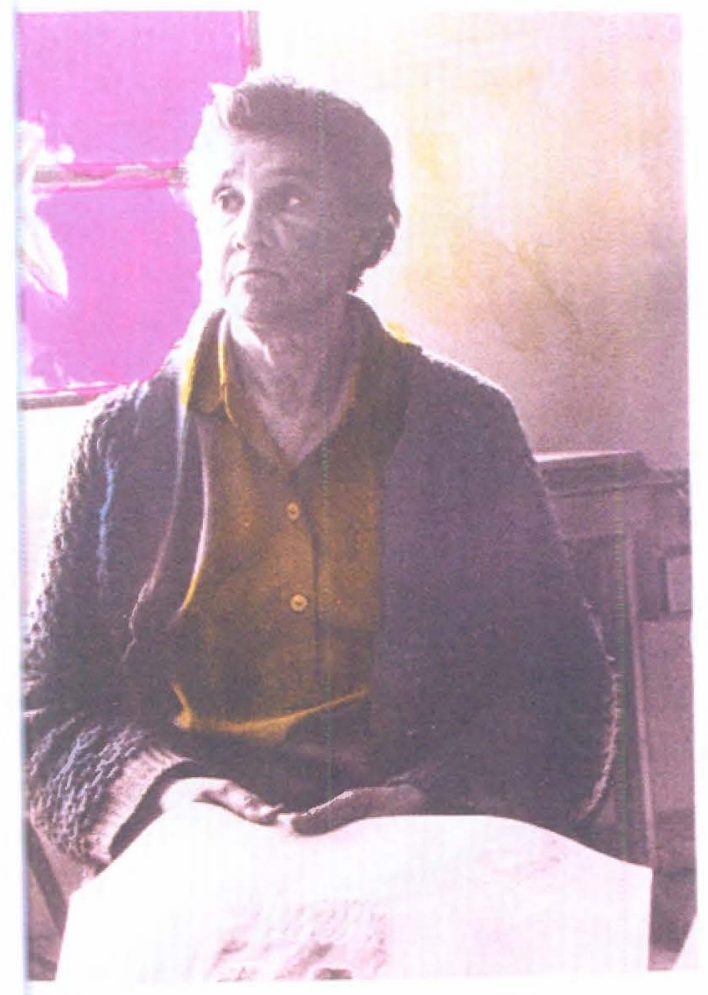




\section{Debreagem enunciva}

A enunciação utiliza o recurso de debreagem enunciva, cuja narrativa temporal se apresenta em cronologia inversa, visto que começa com as fotografias das mulheres mais idosas e vai deslocando-se no decorrer do livro para as mais jovens.

A primeira série de imagens faz parte do processo terminativo. pois traz pessoas de mais idade como personagens. Nelas vemos expressões de passividade, de ilusão e de agressividade, pintura com cor forte, falta de coordenação motora - a estereotipia da loucura.

Na série intermediária poderíamos dizer que o processo correspondente seria o inaptivo, pois, apesar da fotografada não ser mais criança, as imagens são de adolescentes, e passam uma sensação de ingenuidade, espontaneidade, alegria, típicas de crianças. Idade do mundo encantado, do "tudo azul", talvez seja por isso que foi tão utilizada esta cor nas interferências desta etapa do livro.

E a série final seria uma ponte entre o processo terminativo e inaptivo, a época da descoberta da mulher, quando a ingenuidade vai ficando para trás e há uma busca pela sexualidade, pela sensualidade e pelo desejo. O uso mais recorrente de interferência foi a pintura no rosto como se fosse uma maquiagem, ou seja, a forma estereotipada da vaidade feminina.

Com as interferências na maioria das fotografias, o foco narrativo pode variar, já que se pode mudar o ponto de vista ou alterar o campo do olhar. Cria-se uma segunda debreagem, ressaltada pelo modo como as imagens foram registradas (pelas escolhas técnicas, principalmente quanto à lente utilizada), o que produz um efeito de sentido de narração em primeira pessoa, uma focalização parcial interna, pois o ponto de vista de fora para dentro da imagem é como se o espectador participasse da ação.

Isto fica mais evidente com relação à moldura da imagem. $\mathrm{A}$ fotografia, por uma determinação técnica, é um emolduramento de uma cena, recorta uma realidade, delimitando um espaço. Algumas intervenções feitas pelas fotografadas re-delimitam esta imagen, desenhando uma nova moldura para a cena. As molduras aparecem desenhadas em cores diferentes das utilizadas no seu interior, o que 
reforça o campo visual interno, conferindo maior importância ao que se passa dentro do quadro. $\mathrm{Na}$ fotografia 3, o espaço da significação ganha uma força diferente, porque o desenho da moldura é a única interferência sofrida pela imagem, como se o enunciadorenunciatário dissesse: "Eu sou a fotografia".

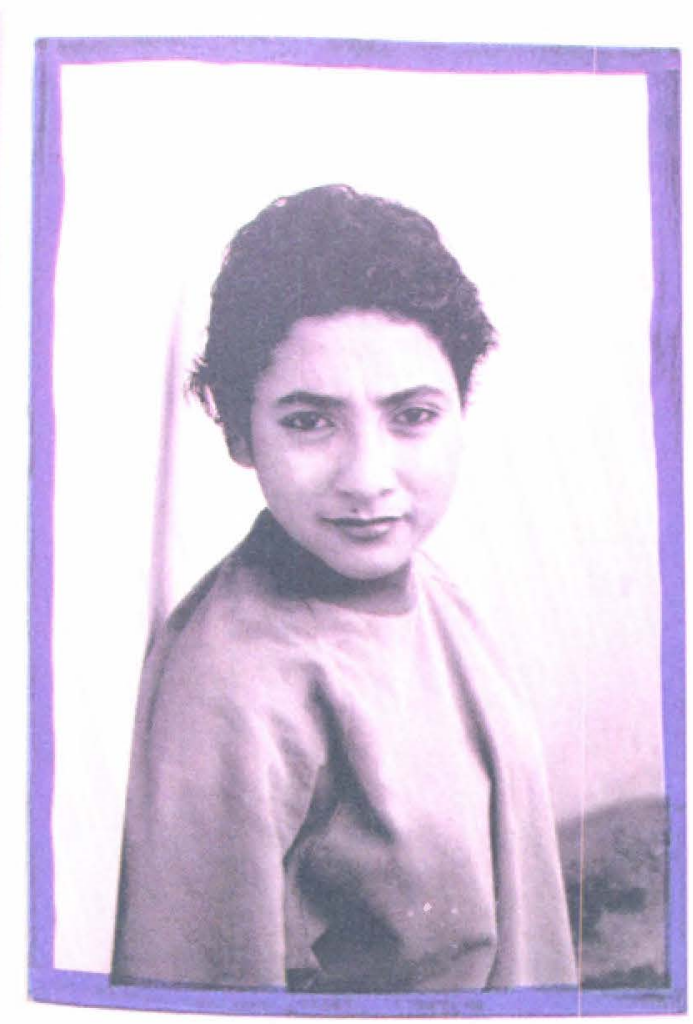

Em outras imagens, a moldura, desenhada, apresenta-se deslocada de sua função primeira, que seria a delimitação do campo visual geral da cena, e aparece interna aos limites da fotografia. Nesse caso, a noldura serve de espaço interno ao mesmo tempo, pois foi desenhada e pintada, deixando apenas o rosto como objeto da enunciação. Aqui, o mesmo efeito de sentido do ell-sujeito da fotografia aparece mediante uma forma expressiva diferente. 


\section{Polissemia - as vozes no texto}

Este texto apresenta o recurso da diversidade de olhares bem demarcado, trabalhado de três maneiras: o olhar de fora para dentro, o olhar de dentro para fora e o olhar de dentro para dentro.

O olhar de fora para dentro é demarcado pelo olhar da fotógrafa, quando delimitou o campo do olhar pelo visor da câmera fotográfica, e pelo da fotografada quando interviu com o desenho de uma nova moldura, re-delimitando o campo de significação da imagem.

O olhar de dentro para fora é percebido quando a fotografada direciona o seu olhar para câmera, criando uma ilusão de que está olhando diretamente para o destinatário da imagem.

E o olhar de dentro para dentro é delimitado quando a fotografada dirige seu olhar para dentro do espaço de significação, olhando além das margens da fotografia, para o que ficou de fora do campo de visão do espectador, mas que ainda assim faz parte do campo do olhar do enunciatário.

Esse jogo de olhares possibilita várias leituras, incrementadas pelo fator da interferência possível nestas imagens. Assim, a delimitação da foto em forma de moldura possibilita a leitura: "Eu sou o quadro"; a pintura do fundo: "Eu sou o humano"; e a demarcação do rosto feminino pela maquiagem: "Eu sou a mulher".

A polissemia é trabalhada aqui, não só na linguagem fotográfica, mas também na edição das imagens e na intervenção posterior trazendo consigo o discurso da loucura, da inocência, da vaidade, da sedução. Estes diferentes discursos aparecem sob forma de óculos sociais com os quais estamos acostumados a ver o mundo.

Assim, a estereotipia da loucura permite que se estabeleça uma imagem como fruto de um indivíduo que está internado por problemas psiquiátricos, porque a maneira como este mesmo indivíduo interferiu na fotografia, pintando o seu rosto de maneira pouco estética, (como observamos nas fotografias 1, 4 e 5 de pacientes do Instituto Psiquiátrico José Barack) não é o que reconhecemos como uma "maquiagem" dentro dos padrões convencionais. A "maquiagem" nestas fotografias é utilizada como uma caricatura, um exagero de uma particularidade real. Esta tentativa de ficar boni- 
ta de form a caricata é uma leitura inversa da cultura do glamour, da moda, da beleza feminina como a conhecemos.
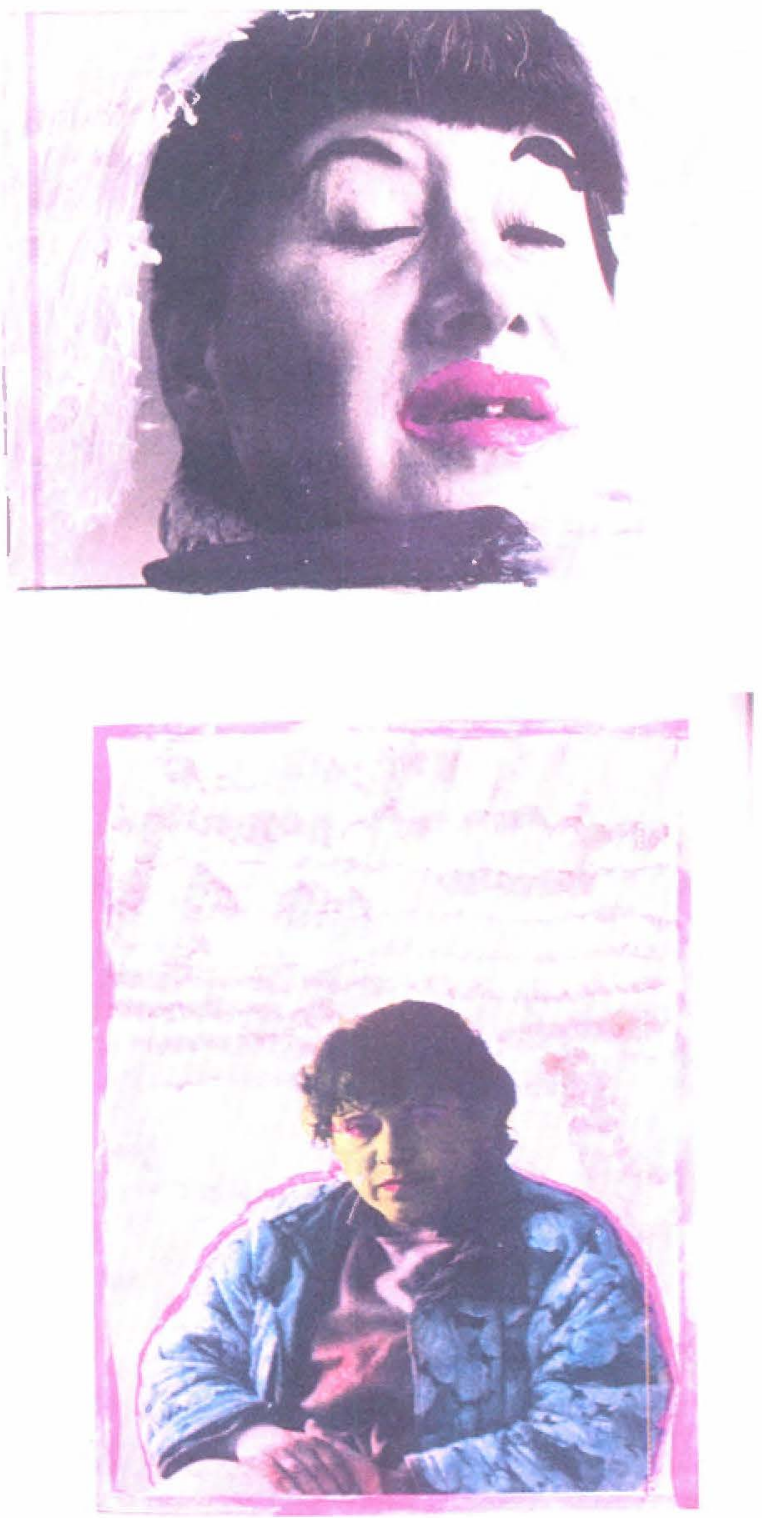
O mesmo acontece nas fotografias em que aparecem intervenções mais agressivas, com cores muito fortes e com pouco apelo estético. O interessante aqui é que este mesmo signo - a interferência posterior em uma fotografia, principalmente no rosto, de modo não convencional - utilizado em outro contexto, motivou um significado completamente diferente. Neste caso, a enunciação era em um catálogo de moda e o estereótipo da loucura foi conotado como algo "fashion", "glamouroso", pelos espectadores desse discurso. A leitura foi feita, neste exemplo, pelo dialogismo, pela negação do discurso da cultura de moda convencional.

A vaidade e a sedução, como forma de expressão, aparecem nas imagens (mais de um terço das fotografias editadas!) de maneiras diferentes. Nas primeiras imagens, a vaidade aparece apenas quando houve a intervenção posterior à captação fotográfica, o que demonstra um simulacro de como gostariam de se ver representadas perante 0 olhar do outro. Na maioria delas, o exagero e a aparente falta de coordenação motora ao elaborar esta "maquiagem" remetem à questão da loucura tratada acima, e adquirem um valor pejorativo.

Nas outras fotografias, a vaidade e a sedução manifestam-se pela estereotipia da imagem feminina; o olhar de algumas delas e a pintura do rosto relacionam-se com a maquiagem da mulher: o batom na boca, olhos delineados, o rímel nos cílios e pintas que trazem à memória o estereótipo da mulher sensual, Marilyn Monroe, ou mais recentemente a top-model Cindy Crawford.

\section{A descrição e a narratividade}

Individualmente, as fotos podem ser consideradas um texto visual descritivo por serem retratos, nos quais o fato é registrado simultaneamente ao acontecer. Porém, ao analisarmos a obra completa, fotografia e pintura, verifica-se que há uma simulação de simultaneidade, já que as interferências foram feitas posteriormente pelas fotografadas. Podemos dizer, então, que estas fotos são um texto descritivo que contém uma transformação - 0 antes e o depois da pintura - típica de textos que contém narratividade. A pintura seria o componente narrativo deste texto, transformando, em alguns casos, o estado de alma da personagem. 
Na foto original, o estado de alma da personagem é demarcado principalmente pela expressão facial da fotografada, e, com a interferência da pintura, em alguns casos há uma transformação, uma confirmaçăo, ou um exagero deste estado de alma.

Trmando como exemplo a folografia 6 , observa-se que a pintura posterior da imagem transforma a expressão facial da fotografada, pois o uso de uma cor forte, um rosa intenso, tanto na moldura como na simulação de um batom, traz agressividade, principalmente ao rosto da personagem. O fato da pintura năo corresponder ao que se convenciona chamar de padrão normal reforça esse aspecto, pois a t nta rosa, além de borrada, forma gotas ao redor da boca da fotogratada nos dando a impressão de sangue - o gosto de sangue na boca construindo um efeito de sentido de agressividade.

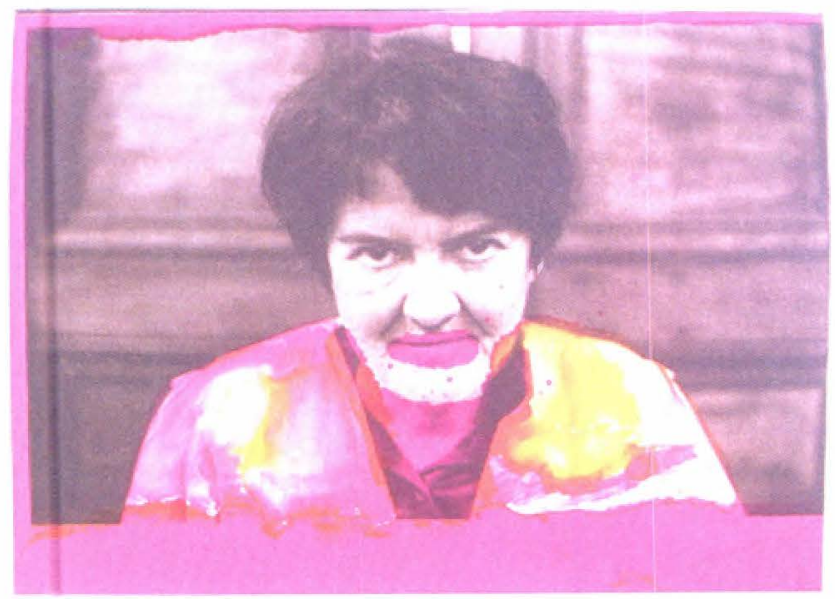

Na fotografia 1, a agressividade aparente do olhar da fotografada, con as sobrancelhas arqueadas, é exagerada pelas cores e pela forma əmpregada na pintura. Cores fortes en todo o espaço ao redor da personagem, o rosto borrado em rosa vibrante, sem nenhuma preocuração estética, levam o olhar do espectador a um campo de visão que é produto apenas da fotografia, sem interferência alguma - os olhos da fotografada. 
A construção de um estado de alma que busca a sedução é confirmada pela interferência produzida pela pintura na fotografia 7. A garota fotografada posiciona-se quase de perfil, uma mecha do cabelo projeta-se sobre um dos olhos produzindo um olhar em diagonal, um pouco mistério e um pouco desejo. A pintura posterior confirma esse efeito de ilusão de sensualidade porque a maquiagem elaborada utiliza um batom de cor forte, bem demarcado, os olhos foram delineados e o desenho de duas pintas no rosto remete à pinta famosa da top-model Cindy Crawford: um pouco acima da boca, no lado esquerdo.

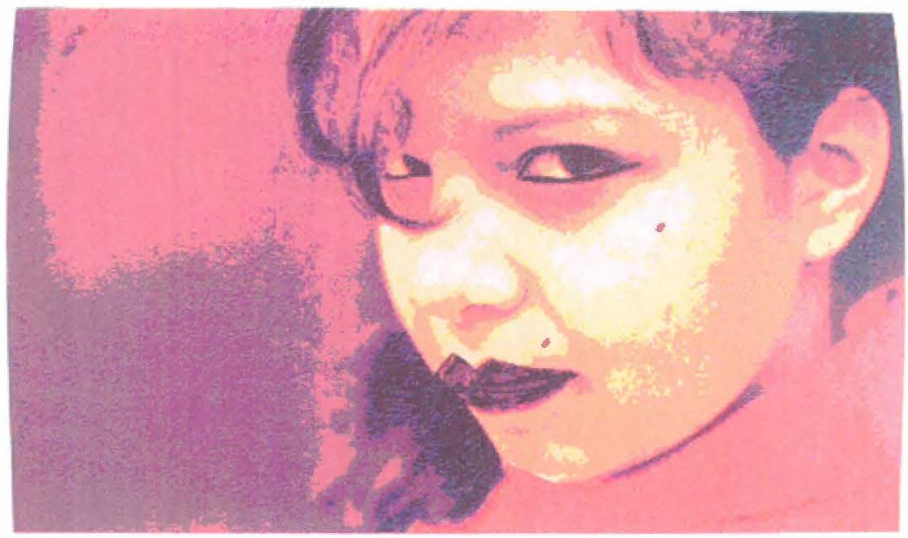

\section{Conclusão}

A análise do texto Autoimagen marginal', produzido em co-autoria fotógrafa e fotografada, retoma em cada aspecto explorado neste artigo a questão da busca da identidade feminina e da forma em que esta identidade se manifesta em mulheres que se encontram privadas da liberdade plena de expressão, seja por problemas

1. O livro Autoimagen marginal foi elaborado junto às pacientes do Instituto Psiquiátrico José Barack e junto às reclusas do Centro de Niñas del Servicio Nacional del Menor e no Centro de Niñas Menores en Riesgo Social, todos em Santiago, no Chile, durante o período de 1993 a 1997. 
psiquiátricos - a questão da loucura - seja por problemas de recuperação social - a questão da subversão social.

O fato de que estas mulheres não têm acesso a espelhos nestes locais em que se encontram enclausuradas reforça a característica especular da fotografia. A imagem fotográfica, enquanto processo físico e químico que se submete a um potencial representativo, surge, então, como o próprio espelho, a fotografia-espelho, o ponto de encontro da identidade esquecida das mulheres fotografadas.

E a possibilidade de escolha da fotografía a ser editada e a posterior interferência pela própria fotografada permitem a exteriorização de imagens mentais que essa mulher tem de si mesma, confirmam-se como expressão-enunciação, como tradução de uma representatividade ignorada, como recuperação da feminilidade perdida.

\section{Bibliografia}

BAKHTIN, M. 1997 Marxismo e filosofia da linguagem. 8 ed. Traduzido por Michel Lahud e Yara Frateschi Vieira. São Paulo: Hucitec. 1997.

BARROS, D. L. P.de. 1997 Teoria semiótica do texto. $3^{a}$ ed.. São Paulo: Ática, 1997.

BARTHES. R. 1984 A Camara Clara: nota sobre a fotografia. $7^{a}$ impressão. Traduzido por Júlio Castañon Guimarães. Rio de Janeiro: Nova Fronteira, 1984.

DUBOIS, Ph. 1994 O ato fotográfico e outros ensatos. Campinas: Papirus..

FIORIN, J.L.1999 As astúcias da enunciação. $2^{a}$ ed.. São Paulo:Ática.

989. Elementos de análise do discurso. $8^{a}$ ed.. São Paulo:Contexto/Edusp (Col. Repensando a Língua Portuguesa).

FIORIN, J.L.e PLATÃ O, F.S.2000. Lições de Texto-leitura e redação. $4^{a}$ ed.. São Paulo: Ática.

KOSSOY, B. 2000. Realidades e ficções na trana fotográfica. $2^{a}$ ed.. São Paulo: Aceliê.

RUMAN, E. 1998. Autoimagen marginal. $1^{\text {a }}$ ed.. Santiago: LOM Ediciones. 